\title{
Analysis of the Relationship Between Railway and Highway Transportation and China's Economic Development
}

\author{
Shibo Ma \\ School of Economics and Management, Tiangong University, Tianjin 300387, China
}

\begin{abstract}
China has a vast land area and frequent interconnections between various regions. China's transportation industry is faced with tremendous pressure. This article combines China's railway and highway transportation conditions to predict China's economic development, uses stepwise regression to screen explanatory variables, and finally determines railway passenger turnover, road freight volume and passenger car ownership as the explanatory variables, and GDP as the dependent variable, and also analyzes China's economic development by establishing a multiple regression model.
\end{abstract}

Key words: Rail transport; Road transport; Multiple linear regression model; Stepwise regression

Publication date: April, 2021; Publication online: 30 April, 2021

*Corresponding author: Shibo Ma, Mashibo74@163.com

\section{Introduction}

China has a vast land area, and different regions have their own unique resources and industries. China's transportation is particularly important. At present, both passenger and freight transportation in China are still dominated by road and rail transportation. Therefore, this article explores the relationship between transportation and China's economic development based on the data of railway transportation and road transportation ${ }^{[1]}$.

\section{Regression analysis of road transportation, railway transportation and national economic development}

The multiple linear regression model determines the relationship between the dependent variable $\mathrm{Y}$ and the independent variable $\mathrm{X}$ and establishes a linear regression equation containing independent variable parameters and

Table 1. Regression model estimation disturbance terms to predict the dependent variable ${ }^{[2]}$. The regression model is set as follows:

$Y=\beta_{0}+\beta_{0} X_{1}+\beta_{2} X_{2}+\cdots+\beta_{i} X_{i}+\varepsilon$

In the above formula, $Y$ represents the dependent variable, $\beta_{i}$ is the undetermined parameter, $X_{i}$ is the selected explanatory variable, and $\varepsilon$ is the model disturbance factor. After removing the three variables that are weakly correlated with GDP, this article applies stepwise regression analysis method to analyze the relationship between GDP and the remaining influencing factors, selecting the significant effect factors as independent variables, and establishing the optimal regression equation. Then use the optimal regression equation for regression analysis to determine the degree of relationship between the influence factors and the dependent variable, the results shown in Table 1.

\begin{tabular}{cccc}
\hline & Model(1) & Model(2) & Model(3) \\
\hline Railway passenger turnover & $83.76^{* * *}$ & $64.97^{* * *}$ & $39.47^{* * *}$ \\
Bus ownership & $(40.58)$ & $(7.77)$ & $(6.95)$ \\
& & $4.47^{* *}$ & $5.50^{* * *}$ \\
& & $(1.80)$ & $(1.08)$
\end{tabular}




$\begin{array}{cccc} & & & (4.87) \\ \mathrm{C} & -312040.6^{* * *} & -375925.7^{* * *} & -358596.1^{* * *} \\ \text { Adj.R } & (-16.20) & (-12.34) & (-1.51) \\ \text { DW Statistics } & 0.9922 & 0.9948 & 0.9984 \\ & 1.1566 & 0.9912 & 1.6981\end{array}$

Note: $* * *, * *, *$ represent significant at the level of $1 \%, 5 \%$, and $10 \%$

Finally build the model:

$\mathrm{GDP}=-358596.1+39.47483 \mathrm{X}_{7}+5.495889 \mathrm{X}_{12}+$ $0.066020 \mathrm{X}_{6}$

$$
\begin{array}{lrr}
(-19.62478) & (5.676824) \quad(5.082515) \quad(4.865) \\
R^{2}=0.998358 & F=2229.729 \quad D W=1.698107
\end{array}
$$

According to the model, it can be seen that when railway passenger turnover increases by 100 million passengers per kilometer, China's GDP will rise by 3.947483 billion yuan; when the number of passenger cars increases by 10,000, China's GDP will rise by 5.495889 billion. When the road freight volume increases by 10,000 tons, China's gross national product will rise by 60602 million yuan.

\section{Analysis of transport intensity}

Transportation intensity refers to the transportation passenger and cargo conversion turnover in a certain period of time to the gross national product of the same period. It is a commonly used analysis index reflecting the relationship between transportation and economic development.

The calculation formula of transportation intensity is:

Transport intensity $=$

$\frac{\text { Transportation passenger and cargo conversion turnover }}{G D P}$

According to the data of China's gross national income, railway passenger turnover, and railway freight turnover from 2003 to 2017 , the transportation intensity is calculated. The annual change trend of transportation intensity is shown in Figure 1.

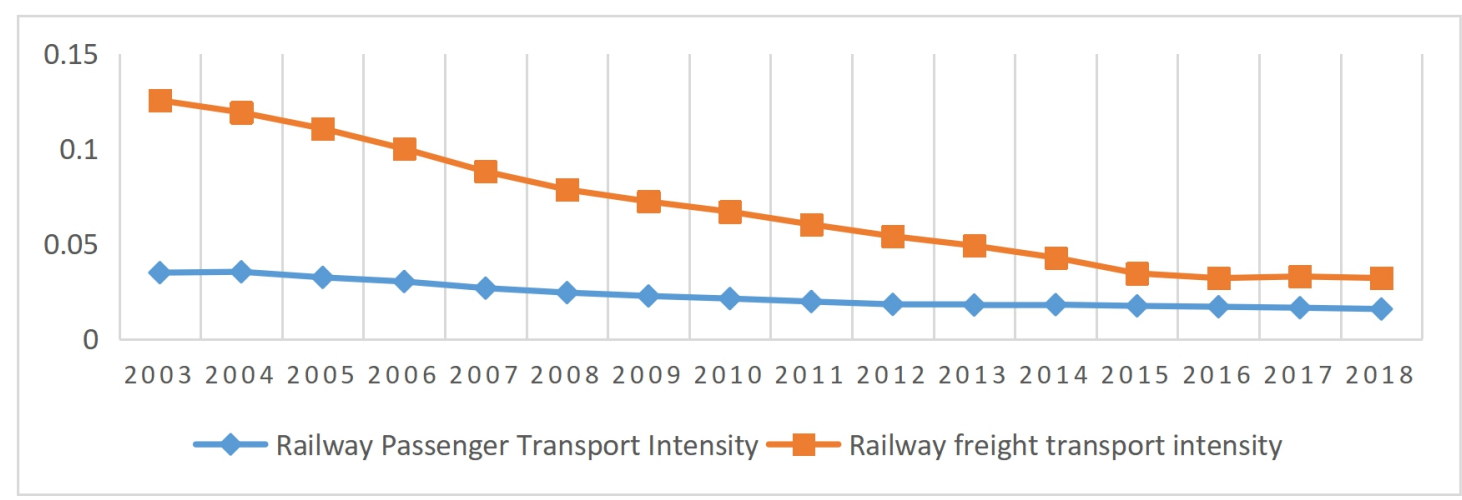

Figure 1. Transportation intensity change trend chart

According to the change trend of transportation intensity in Figure 1, it can be found that from 2003 to 2018, China's railway passenger and freight transportation intensity has maintained a downward trend. The reason for this phenomenon is partly due to the vigorous development of various industries in China. The industrial structure of China has gradually become complete, and the shortage of resources has gradually declined, shortening the transportation distance between production areas and processing areas. On the other hand, with the continuous economic development of China in recent years, the transportation structure is gradually improving. Part of the pressure on railway passenger and freight is shared by road, water and air transportation, which also makes the intensity of railway passenger and freight gradually decline.

\section{Transportation elasticity analysis}

Transportation elasticity is the transportation elasticity coefficient obtained from the ratio between the growth rate of each transportation index involved in this article and the growth rate of the gross national economy to judge the relationship between transportation and the national economy. Suppose $E_{1}$ is the elasticity of road freight volume, $E_{2}$ is the elasticity of passenger car ownership, $E_{3}$ is the elasticity of railway passenger turnover; $r_{1}$ is the growth rate of road transportation freight volume, $r_{2}$ is the growth rate of 
passenger car ownership, $r_{3}$ is the growth rate of railway transportation turnover, R Is the GDP growth rate.

$E_{i}=\frac{r_{i}}{R}$

Based on China's 2003 2018 GDP growth rate, railway transportation turnover growth rate, passenger car ownership growth rate and road freight volume growth rate, the elasticity coefficient is calculated according to formula (4), and the results are shown in Figure 2.

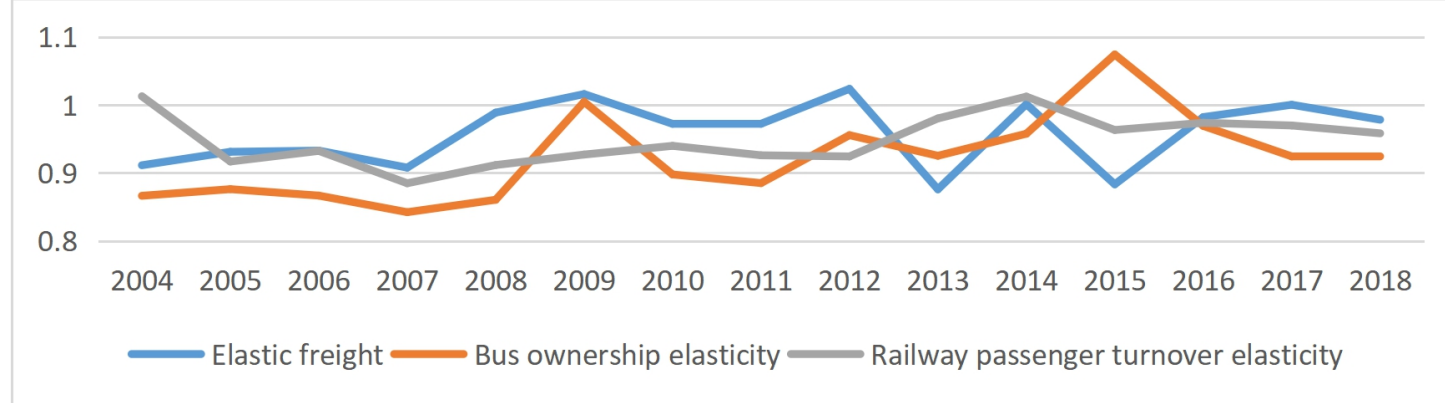

Figure 2. Elastic change trend graphs

\subsection{Analysis on the changing trend of the elastic coefficient of railway passenger turnover}

From the perspective of the elasticity coefficient of railway passenger turnover, $E_{3}$ in 2004 and 2014 were both greater than 1 , indicating that the growth rate of railway passenger turnover in that year was greater than that of GDP, and the railway passenger turnover promoted China's economic development. The elasticity coefficient of railway passenger turnover in other years is between 0 and 1, indicating that the growth rate of railway passenger turnover is less than that of GDP, relative to the change in GDP, the railway passenger turnover change slightly.

\subsection{Analysis on the change trend of the elastic coefficient of passenger car ownership}

From the perspective of the change trend of the elasticity coefficient of passenger car ownership, the elasticity coefficient of passenger car ownership in 2009 and 2015 was greater than 1, indicating that in these two years, the growth rate of passenger car ownership was greater than the growth rate of GDP, and the growth rate of passenger car ownership Can promote the development of China's economy. Take 2009 as an example. After experiencing the subprime mortgage crisis in 2008, China introduced numerous fiscal and monetary policies to support the development of the domestic economy. The changing trend of the elastic coefficient of passenger car ownership also reflects the effectiveness of China's macro-control policies.

\section{Analysis on the changing trend of the elastic coefficient of road freight transport}

From the perspective of the elasticity coefficient of road freight, except for 2009, 2012 and 2017, the elasticity coefficient of road freight is between 0 and 1 , which is inelastic, indicating that the growth rate of GDP is greater than that of road freight transportation. Changes in freight transportation caused by GDP changes are relatively small. For the three years of 2009, 2012 and 2017, the elasticity coefficient of road freight is greater than 1 , indicating that the development of road freight has driven the overall social and economic development of China.

\section{Conclusion}

Compared with other factors, railway passenger turnover $\left(\mathrm{X}_{7}\right)$, road freight volume $\left(\mathrm{X}_{6}\right)$ and passenger car ownership $\left(\mathrm{X}_{12}\right)$ are more significant in promoting China's economic development. Continuing to improve the railway and highway transportation network can promote the development of China's economy, which is one of the important factors influencing the steady growth of China's economy ${ }^{[3]}$.

In terms of suggestions, a systematic railway and road transportation network should be established first. From the perspective of the changing trend of railway passenger turnover and road freight volume, railway passenger transportation and road freight transportation have a high degree of impact on China's economic development. Most of China's materials are transported by road, but China's road transportation system still needs to be improved. Good road conditions and lower highway tolls can save freight time and freight costs. At the same time, it can also share the freight pressure of the railway system, so that the development of the two modes of transportation will be announced and promote China's economic growth. 


\section{References}

[1] Wang XF, et al. Economic route selection under the integrated operation mode: Case study of China railway

[2] He J. Application of deep learning model under improved EMD in railway transportation investment benefits and national economic attribute analysis[J].

The Journal of Supercomputing, 2021: 1-15. express in Zhengzhou[J]. International Journal of Shipping and Transport Logistics, 2021, 13(3-4).

[3] Nojiri W, Jiang X. On the railway freight transport in China[J]. Geographical Review of Japan, 2007, 80(12) : 804-820. 